\title{
Challenges in Saudi Universities' Shift Toward a Knowledge Society
}

\author{
Ali S. Al-Shayea Ph.D. \\ Associate Prof. of Educational Management \& Planning \\ College of Education- Qassim University, Saudi Arabia \\ ashayea@qu.edu.sa
}

\begin{abstract}
Higher education in Saudi Arabia is facing several challenges posed by a set of transformations in society in general, and the economy in particular. As economies become increasingly knowledge-based, universities bear the burden of helping the community transform into a knowledge society. This paper focuses on the most important challenges facing Saudi universities as they shift toward becoming contributors to a knowledge society. Using a descriptive analytical approach, data was collected from several studies and published statistics. A range of challenges was discovered, the most important of them are a heavy reliance on government funding, poor productivity of faculty members, the gap between the outputs of universities and the labor market, the absence of strategic planning for higher education, the absence of a national strategy for scientific research, and the weakness of the relationship between undergraduate majors and the needs of the community.
\end{abstract}

\section{Indexing terms/Keywords}

Keywords: Higher education, Saudi Arabia, knowledge society

\section{Academic Discipline And Sub-Disciplines}

Education; Sociology; Cultural Studies;

\section{SUBJECT CLASSIFICATION}

Education Classification

\section{TYPE (METHOD/APPROACH)}

EducationalAnalysis Approach ; Survey/lnterview

\section{Council for Innovative Research}

Peer Review Research Publishing System

\section{Journal: Journal of Social Sciences Research}

Vol. 9, No.1

jssreditor.cir@gmail.com

www.jssronline.com 


\section{INTRODUCTION}

Universities are a primary source of new knowledge. As society becomes increasingly knowledge -bas ed, universities are more often responsible for shouldering many of its burdens. In particular, advances in knowledge made by the university are a significant part of the social contract that leads to human development. For this reason, an effective and dynamic system of knowledge creation is extremely important for developing countries. One of the greatest demands currently challenging many universities, therefore, is the need to develop an effective process of change in a new era characterized by large transformations in the requirements for competing in a global knowledge-based society.

As stated, the shift toward a knowledge-based society is a process that has many implications for higher education, as universities have a significant role in the creation of knowledge. Indeed, universities face huge challenges that have an effect on their ability to carry out this role. Many Saudi universities must now explore how to develop institutional structu res that adequately monitor university performance, and maintain the ability to meet society's urgent requirements for change. In response to this demand, Saudi universities are now reconsidering administrative methods and philosophies concerning university and knowledge management in a knowledge-based economy (Al-Thoubirty, 2002, p. 35).

\section{Problem of the Study}

Knowledge has become a focus of many countries that realize its importance in bringing about sustainable development. Similarly, knowledge has also become a focus among international companies that seek to maintain their productivity and position globally. This focus on knowledge revolves around the concept of establishing the so-called "knowledge society." According to the 2002 Arab Human Development Report, the most crucial aspect of the education crisis in the Arab world is its current educational system's inability to meet the developing needs of Arab societies. Arab countries have not been innovators in knowledge, information, or the technical world. If this situation is continued, the cris is in Arab countries co uld become worse.

In spite of the importance of knowledge, the first Arab Cultural Development Report, prepared by the Arab Thought Foundation in 2008, argues that before Arab states can improve and achieve effective human development through the establishment of the knowledge society, an important first-step must be made. Namely, there must be significant improvements in the quality of the higher education in the Arab region. Looking at the importance of Saudi universities and their role in becoming a knowledge society, this study explores the following question: What are the challenges facing Saudi universities in the shift toward a knowledge society?

\section{Importance of the Study}

This study derives its importance by exploring challenges facing higher education, which is considered an independent variable in both economic and social aspects of the development process, and a necessary condition for achieving progress in its various forms, either physical or non-physical. As confimed through many studies, conferences, and seminars, education in general, and higher education in particular, is an essential requirement for the achievement of the development in our contemporary era.

\section{Methodology of the Study}

The study is base Higher education in Saudi Arabia is facing several challenges posed by a set of transformations in society in general, and the economy in particular. As economies become increasingly knowledge-based, universities bear the burden of helping the community transform into a knowledge society. This paper focuses on the most important challenges facing Saudi universities as they shift toward becoming contributors to a knowledge society. Using a descriptive analytical approach, data was collected from several studies and published statistics. A range of challenges was discovered, the most important of them are a heavy reliance on government funding, poor productivity of faculty members, the gap between the outputs of universities and the labor market, the absence of strategic planning for higher education, the absence of a national strategy for scientific research, and the weakness of the relationship between undergraduate majors and the needs of the community.

Keywords: Higher education, Saudi Arabia, knowledge society

$\mathrm{d}$ on the descriptive approach. Data was collected from several studies and published statistics.

\section{Literature Review}

\section{The Emergence of Higher Education in Saudi Arabia}

Higher education in Saudi Arabia developed in the context of objectives set forth in comprehensive development plans drawn up by the state for the modernization and advancement of society. The development of adequate human resources is one of the leading objectives sought to be achieved by successive and continuous plans that focus on raising the efficiency of those resources.

As the aims ofhigher education in the Kingdom of Saudi Arabia become more responsive to social and economic needs, so too do formal plans established by the government. The Eighth Development Plan to develop higher education in the Kingdom focuses on quality and quantity in higher education through the following objectives:

1. Provide highereducationopportunities for citizenswhodesiretocontinueuniversity studies . 
2. Broaden the base ofeducationin line with therequirements ofeconomic and social development.

3. Achieveahigherdegreeofawarenessandeffectiveness, and increase the scientificandadminis trativeperformanceinthehighereducationsystemand its institutions.

the efficiencyof

4. Activate the work ofinstitutions of higher educationin the service ofs ociety.

5. Build the capacity ofs cientificresearchand technical developmentand its promotion (Ministry ofEconomy and Planning, 2005, p 444).

\section{Higher Education Goals}

In addition to the objectives identified in the Eighth Development Plan, the Ministry of Higher Education has enumerated the following objectives:

1. Development of the doctrine conceming loyalty to God, and the follow-up necessary to give students from the Islamic culture a sense of responsibility before God and the nation of Islam to engage in useful and fruitful scientific endeavors.

2. Preparation of competent citizens who are scientifically and intellectually qualified to perform their duties in the service of their country, and advance their nation according to Islamic faith and principles.

3. Provide excellent students with opportunities for postgraduate studies in various scientific disciplines.

4. Make positive contributions to scientific research that contributes to global progress in art, science, and invention, and find appropriate solutions to societal issues using advanced technological techniques.

5. Promote scientific authoring and production that contributes to Islamic ideas. Also, contribute to the building of human civilization on the principles of the authentic human, which leads humanity to righteousness and rationality, and promotes avoidance of distractions and atheistic materialism.

6. Translate science and us eful arts to the language of Koran, and make knowledge accessible to the greatest number of citizens.

7. Undertake studies and training services that are "innovative," or assist graduates in the field of work after graduation (Ministry of Higher Education, 1421, p. 4).

Overall, the objectives of higher education in the Kingdom illustrate the great concern had by those who support them, as well as what is hoped for. However, the observer may note that there is a range of challenges facing the Saudi universities that make attaining the aspirations of the community and keeping up with global changes difficult, including:

1. Financing higher education,

2. Faculty productivity in scientific research,

3. Post-graduation employability and the labor market,

4. A lack of strategic planning in higher education,

5. The absence of a national strategy for scientific research, and

6. The relations hip between undergraduate majors and the needs of the community.

\section{Financing Higher Education: Heavy Reliance on Government Funding}

Article 233 of the education policy in the Kingdom of Saudi Arabia states that education is to be free at all levels, and the re shall be the granting of monthly bonuses and the provision services for all students. Therefore, the majority of higher education institutions depend fully on government support. The average spent on public higher education is about $25 \%$ of all government spending (Habib, 2006, p. 61). Increasingly complex finance-related problems, along with growing trends that call for increased effectiveness and raise the level of efficiency and quality further complicate financing in higher education. In particular, a lack of resources, decreases in government budgets, inflation, etc. may make it difficult for universities to fulfill their roles. Overall, financing difficulties in institutions of higher education may lead to a decline in both internal and external efficiency.

\section{Faculty Productivity in Scientific Research}

Scientific research is one of the basic university functions, along with a leading role in the service of society in terms of its development and prosperity. Without scientific research, the university becomes no different than any other educational institution. Conversely, without an education function, the university becomes a purely scientific research institution. Therefore, it is important that universities maintain both educational and scientific research functions. Some universities, however, do not adequately fulfill their research roles.

The education policy in the Kingdom of Saudi Arabia (1416) emphasizes the importance of scientific production, where three of the seven goals of higher education focus on production and scientific research. Most of the research conducted by faculty members is traditionally used by the researcher for promotion; however, these promotions may be delayed for 
several years. As a result, much of the research produced in Saudi universities remains local in nature, and creativity is limited or abrogated. As noted by Manea (2008), "It is rare to find striking research at the scientific level" (p. 8).

The rate of the general scientific production for faculty members in the Umm Al-Qura University, for example, is 0.4 per year. When excluding members who did not publish any scientific work, the rate improves to reach up to 0.7 works per year, which is less than what is required globally. Approximately $38.4 \%$ of faculty have not publish any scientific work since receiving a Ph.D. Sixty percent are dissatisfied with the scientific productivity. It has also been confirmed that there is a positive correlation of 0.5 between a high rate of scientific productivity and the years of experience of the faculty member (Al-Zahrani, 1417).

Another study on the rate of research productivity among faculty members at the Islamic University of Imam Muhammad bin Saud found that the rate of scientific production among faculty at that university was 0.43 works for each member per year. When non-active members were excluded, the rate increased to reach 0.52 works a year. The rate of scientific productivity among professors reached to 0.87 works annually. This rate was higher than their colleagues of associate professors and assistants, where the annual production rate was 0.48 and 0.24 , respectively. Findings from the study also showed that $73.4 \%$ of the study sample dissatisfaction with their scientific productivity (Architecture \& Al-Balawi, 1422).

Yet, another study exploring research productivity found that the rate of scientific production for faculty members at King Saud University-Colleges of Humanities found that productivity reached 1.25 works per member per year. The average number of published research, books, and scientific papers was 0.63 with 0.25 books per member per year, and 0.37 papers per member per year (Shaya, 2004).

\section{Post-graduation Employability and the Labor Market}

The educational system is primarily responsible for providing young people with the skills necessary to implement various development plans in consideration of the real requirements of the labor market. Some studies have indicated that there are shortcomings in how higher education programs meet the needs of the public and private sectors in the Kingdom. Beyond its role of educator, is the duty of universities to study and meet the community's overall development needs (Al Qarni, 1990). Algebra (1994) conducted a study examining the relationship between university education and the labor market in Saudi Arabia, and found that government and civilian departments have observed that the scientific skills of university graduates are not directly related to the nature of their work. The study confirmed the need to improve communication among universities, government, and civilian departments (Algebra, 1994).

Algebra's (1994) study also found that there are other major obstacles to students' preparation to contribute to the labor market, including: (a) the behavioral attributes of the graduate, (b) the academic abilities of the graduate, (c) the ability to function as an employee, (d) local wages. Additionally, the study found that there is a discrepancy between what businessmen and education believe can be accomplished by universities in the labor market in Saudi Arabia (Turkestany, 1998). Similarly, another study of private medium and large sector organizations in the Kingdom, found that $77.8 \%$ of the study's sample believed that higher education curricula do not adequately provide the skills required for their organizations (Albahseen, 2006).

\section{Lack of Strategic Planning for Higher Education}

Higher education in Saudi Arabia has experience a renaissance, as a number of universities jumped from seven to more than 20 in less than 10 years. Asiri's (2005) study revealed that society is likely to experience volatil ity when failing to take into account the strategic planning needs of higher education along with the educational challenges resulting from globalization and in linking higher education plans with workforce plans. Similarly, a study conducted by Harthy (2010) found that strategic planning in women's colleges in Saudi universities is only moderate, which contributes to administration that is not qualified in management, in addition to the administrative complexities within the women's colleges, and the difficulties relating to the implementation, monitoring, and evaluation of plans.

\section{The Absence of a National Strategy for Scientific Research}

In general, it can be said that there is little vision or strategy for scientific research in the Arab world at large, a nd in Saudi Arabia in particular. There are few ambitious long-term goals with specific plans to be funded, implemented, supervised, and evaluated according to research priorities and development plans. A study conducted by Salman (1993) indicated that the crisis of scientific research in the Arab world is embodied in the absence of a research clear strategy, resulting in many problems including: budget deficits, limited individual research, and the inability of Arabic scientific institutions to perform its role in leading the nation in scientific endeavors. Ghanem (2000) also confimed these findings, noting that Arab countries suffer from the absence of a clear scientific policy. Similarly, Elsaid (2007) concluded that the Arab countries in general lack a means of drawing national research policies, and coordinating and planning programs to stimulate to social and economic development.

Despite the improved planning efforts of government institutions in the Kingdom of Saudi Arabia, planning for scientific research is still less than ambitious. Manea (2002) discussed the weakness of planning in higher education, especially as it relates to the goal of scientific research. This is reflected in the lack of interest in scientific research in terms of its development, as well as poor efforts to attract distinguished researchers and professors to support research centers, and failure to link scientific research programs and postgraduate studies with the problems of the environment and society. AlKhatib (2003) noted that the problem of scientific research in Arab universities is also embodied in the absence of a general philos ophy of scientific research, as well as the absence of appropriate mechanisms to achieve this philosophy ( $p$. 124). In light of the absence of a national strategy for scientific research, thereisageneralsense in the 
academiccommunityof the shortage of contributions in scientificresearchmade by researchers from Saudi universitiesattheglobal-level, andafailuretoprovidescientific solutionstocommunity problemsand concerns(Saegh etal., 2008, p. 56).

\section{The Relationship Between Undergraduate Majors and the Needs of the Community}

Current university procedures related to the selection of undergraduate majors do not facilitate the accomplishment of many the development plan goals concerning scientific advancement in several ways. First, the admission procedures for most universities still focus only on the grades obtained by the students at the secondary level, without emphasis on entrance exams and interviews. Secondly, some students are directed to disciplines in which they have little interest, ability, or aptitude. This contributes to students having to repeat classes, dropping out, or changing their major (Kasnawy, 1998). Finally, there is an imbalance in the numbers of students who select interdisciplinary theoretical majors when compared to more applied disciplines and practical specialties, which are needed for vital developmental programs. A study prepared by the Ministry of Higher Education (2008) noted that $80 \%$ of the total numbers of higher education graduates belong to theoretical disciplines, which does little to meet the current needs of the labor market.

\section{REFERENCES}

[1] Aba AlHusein, Samibin Abdullah. (2006). The skills required for the Saudi private sector and the role of higher education in providing: An empirical study, Journal of Economic and Administrative Sciences, Volume 22, Issue 1, King Saud University, Riyadh.

[2] Albunian, Ahmed Abdullah al-Balawi, Ibrahim Youssef. (1422). The reality of scientific production and its obstacles to Saudi faculty members at the University of Imam Muhammad bin Saud Islamic University. Magazine Al-Imam University, No. 36.

[3] Althubaity, Guieber Mater, (2002). Knowledge management and investment in knowledge capital in universities: Analytical theoretical model, Journal of Education and Development, No. 26, the tenth year.

[4] Algebra, Abdullah bin Abdul Latif. (1994). The relationship of university education to the labor market in Saudi Arabia from the point of view of some officials of the governmental and non - governmental departments: An empirical study, Research Center, College of Education, King Saud University, Riyadh.

[5] Al-Harthy, SuadbintFahad. (2010). Strategic planning indicators in girls 'schools in Saudi universities from the point of view of faculty members, Higher Education Symposium girl. Dimensions and aspirations, Taibah University, Me dina.

[6] Alhabib, Fahd Abraham. (2006). The future of higher education in the Kingdom of Saudi Arabia "proposed strategy:" A conference exploring the future of education, The Arab Organization for Administrative Development, 17-21 April, the Arab Republic of Egypt.

[7] Almaneia, Abdullah. (2002). Requirements for upgrading higher education institutions for the development of human resources in the Kingdom of Saudi Arabia: Future perspective, submitted to the Intemational Symposium on "Visions of the future of the Saudi economy even in 1440" Ministry of Planning in the period from 13-17 August 1423 approved 19-23 October 2002, Riyadh.

[8] Al-Qarni, Ali Said. (1990). The relationship between higher education programs and developmental needs of Saudi society, Journal of King Saud University, Educational Sciences, Volume 2, Issue 2.

[9] Al-Saied, Abdul Hamid Mustafa . (2007). Where are we from scientific research? (The study of the reality of scientific research in Arab universities, the first Arab conference entitled: Arab Universities: Future challenges and prospects , during the period from 9-13 December, Rabat.

[10] Al-Shaye, Fahd bin Sulaiman. (2004). Scientific production of faculty members in the colleges of humanities at the University of King Saud and its obstacles, Research presented to a seminar on "Development of faculty members in institutions of higher education: Challenges and development," Held at King Saud University during the period between $2-3 / 11 / 1425$. corresponding to 15-16/12/2004.

[11] Al-Zahrani, Saad Abdullah. (1417). The scientific productivity of faculty members at Umm Al-Qura University Saudis :its reality and obstacles. King Saud University Journal, Volume 9, Educational Sciences and Islamic Studies, Issue 1.

[12] Asiri, Munirabint Mohammed. (2005). The extent to which the planning of the Saudi university education with the harmonization requirements of its outputs and development needs, unpublished Master, King Saud University.

[13] Khatib, Mohammed Shahat. (2003). Higher education: Issues and visions, Dar Khuraiji, Riyadh.

[14] Kasnawy, Mahmoud Mohamed. (1998). Strategy to accept high school students in institutions of higher education in the light of the development plans (in fact - visions of the future), Symposium on Higher Education in the Kingdom of Saudi Arabia visions of the future, in the period from November 25-28, Riyadh, 1418. February 23-26.

[15] Ghanem, Mohamed. (2000). The integration of scientific research in universities and its impact on the Arab Industrial Development, Journal of the Association of Arab Universities, No. 37.

[16] Salman, Rachid Salman. (1993). Cris is of scientific research in the Arab world, Journal of Arab Affairs, No. 75. 


\section{ISSN 2321-1091}

[17] Saegh, Ahmed Abdel-Rahman et al. (2008). Strategic planning for higher education institutions in the Arab countries: The basic features of the preparation of the strategic plan of the College of Education, King Saud University, business conferences strategic planning for institutions of higher education in the Arab world-the Arab Organization for Administrative Development-Arab League, Cairo.

[18] The Arab Human Development Report. (2003). The United Nations Development Program, the Arab Fund for Economic and Social Development, Regional Bureau for Arab States, Jordan.

[19] The Arab Human Development Report. ( 2002 ). The United Nations Development Programmed, the Arab Fund for Economic and Social Development, Regional Bureau for Arab States, Jordan.

[20] The Ministry of Economy and Planning. (2005). The Eighth Development Plan 2005-2009.

[21] The Ministry of Higher Education. (1421). Comprehensive national report on higher education in Saudi Arabia, a report submitted to the First Islamic Conference of Ministers of Higher Education and Scientific Research, held in Riyadh on18-21 Rajab 1421 AH corresponding to15-18 October 2000, Islamic Organization for Education Science and Culture, Riyadh

[22] The Ministry of Higher Education. (2002). Ways to increase the capacity of the university to meet the requirements of future development, provider of the intemational seminarian "visions of the future of the Saudi economy even in 1440 AH "Ministry of Planning in the period from13-17August 1423 corresponding to19-23 October 2002, Riyadh.

[23] Turkestany, Habibullah Mohammad Rahim. (1998). The role of higher education to meet the needs of the Saudi labor market, higher education seminar in Saudi Arabia visions of the future, in the period from November 25-28, Riyadh, 1418

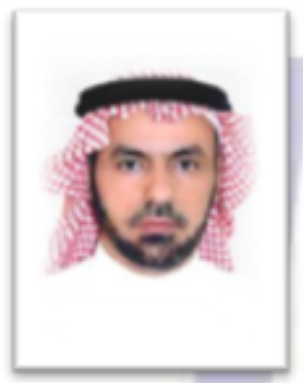

\section{AUTHOR' BIOGRAPHY WITH PHOTO}

Alshayea currently works as an associated professor for the educational administration and planning in foundations of education department in Qassim University. He is a member in many committees in the university as scientific council in Qassim University and The standing co mmittee for training and scholarships. He is an agent for the high studies in the faculty of education.

He worked before as an agent for the educational issues, assistant professor in 2008, a lecturer in the education and psychology dept. in the faculty of science and literature 2002 and he also worked as teaching assistantin the education and psychology dept. in the faculty of teachers in 1998

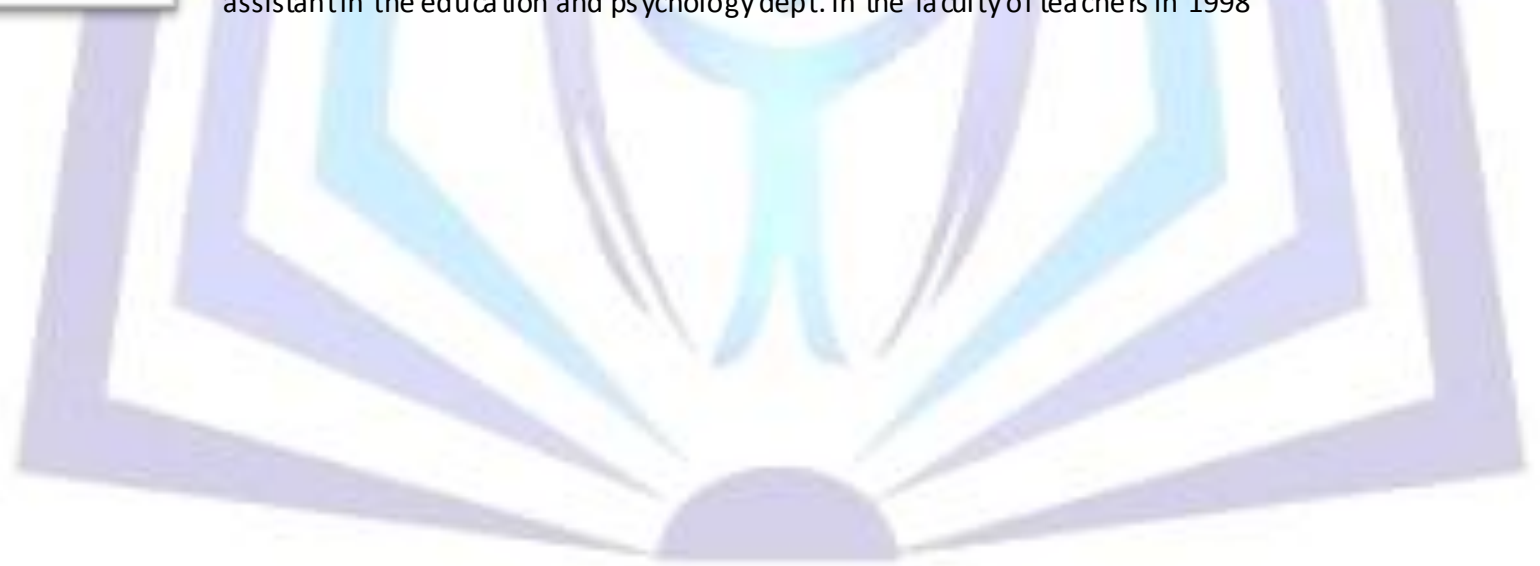

